\title{
DESIGN AND DEVELOPMENT OF COUNTY- LEVEL INFORMATION MANAGEMENT SYSTEM FOR DISEASES AND PESTS OF HEBEI PROVINCE ON GIS
}

\author{
Xiaoyan Cheng ${ }^{1}$, Xiaoli Zhang ${ }^{1, *}$, Fangyi Xie ${ }^{1}$ \\ ${ }^{1}$ Key Laboratory for Silviculture and Conservation, Ministry of Education, Beijing Forestry \\ University, 100083 , P. R. China \\ ${ }^{*}$ Corresponding author, Address: Key Laboratory for Silviculture and Conservation, Ministry \\ of Education, Beijing Forestry University, 100083 , P. R. China, Tel: +86-13681272638, \\ Email:zhang-xl@263.net
}

Abstract: To get a more convenience work in forest application, GIS and information system is used in forestry. GIS technology is used to build an informational management system of forest disease. For the practical requirement, the system is implemented by PDA which works outside to help completing the data collection. The major function of the system is input and output of the forest disease data and processing the report which is based on the criteria report and the assistant function of GIS. This article is aim to discuss about the theory, the process and the critical points of the information system. Besides the general information management system, GIS and PDA is introduced into the diseases system, which could combine the map and the attribute information and realize inventory data reform by PDA. The system is developed with VB and SuperMap Object (SuperMap Company).

Key words: forest diseases, second development, Design, development, PDA, Geographic Information System

\section{INTRODUCTION}

The forest diseases and pests are the main factors of the forest health. With the resource of the forest is more and more deficiency, monitoring the

\footnotetext{
Please use the following format when citing this chapter:
}

Cheng, X., Zhang, X. and Xie, F., 2009, in IFIP International Federation for Information Processing, Volume 294, Computer and Computing Technologies in Agriculture II, Volume 2, eds. D. Li, Z. Chunjiang, (Boston: Springer), pp. 991-1000. 
diseases and pests is becoming important, and it is more important to the economist and ecologist. With the development of the software and hardware, the information management of diseases and pests has a bright future. Be under the reality, we use GIS technology as the second development platform to manage the diseases and pests of HEBEI province and give some decision for the manager by the system. We use VB as the development language and SuperMap Object (SuperMap Company) as the second develop plat in order to provide management and decision-making supports for the managers.

\section{THE NECESSARY AND FEASIBLE}

\subsection{Necessary of developing the system}

Although the information is widely used in every industry, the application in the forestry is not extensive yet. There is a large distance between the resource management, monitor technology, information level and modern development of forest. It is known as: (1) The information circulation is not fluency. The inquirers must go to the sample plot and have the record of subplot, which is more time-wasting. (2) A lot of data is not shared. With the increased data, the usage is not enough without the information. (3) There are many mistakes when calculating the report form. The forest farm staff often makes mistakes with the confusion concepts which are not satisfying the time effectiveness. Especially in some county-level forest prevention station, report is usually delayed. So it is more important to develop an information management system.

The purpose of the system is collecting field data through PDA, and then transferring it to the Server which collect the data and calculate various data without mistakes.

\subsection{Feasible of developing the system}

After understanding the process of serious data collecting and calculating in the forest prevention station, also with a clear idea of the data organization, we choose VB as the development language and SuperMap Object 5.2 (SuperMap Company) as the second development platform to develop the system to fit the practical demand. 


\section{THE SYSTEM DESIGN}

The system is developed with the unity data standard based on VB and SuperMap Object 5.2 XML format is used by PDA which collects the field data and then input it into the system. The system accepts the XML data and input them into database. The system has several functions, include system setup, data management, data query, view edit.

\subsection{Database designing}

Database is aim to initialize the system and output the report form. Above all, setting up several standard sample plots, and surveying every detail data of them is the most important function of it. When there are some data of the standard sample plots, the next step is surveying the other plots and summarizing them as the survey table based on the sample plots data. So the tables of the database include the same diseases level table, survey table, standard record table. And there are other tables which separated by survey way, include pests tree number table, pests ratio table, insect gall table and so on. The other related tables are: the prevent table, the quarter total table, administrative division table, pests code table, diseases code table, rodent damage table and so on.

On the needs of the practical usage, the staff needs to survey every aspect of disease. Different survey way is suggested because of the different disease: including pests' tree number table, pests' ratio table, and insect gall table and so on.

The system need other auxiliary tables include administrative code table, disease code table, pests code table, rodent damage table, user-password table, preventing happen table and quarter total table. These are the entire database which used in setting up the system and output report.

\subsection{The data interface}

Subplot is considered as the fundamental unit in the survey, which every data belongs to is recorded in the survey table. The species of the disease and the same disease level plot or other practical data are recorded in PDA. As the format of XML, the data of PDA is introduced into the system, and the report is exported. Input the data of PDA and filling the survey table by manual, with the prevent table and the data summary are the core text of the system.

The inquirer surveys every subplot to collect the field data by PDA which has the same table with the system. The system has the data-processing interface and the result could be seen by the inquirer. 
The table of the system could be filled out by the inquirer where there is no PDA. After finishing the necessary data, such as the number of the harmed trees, the degree of the diseases, and the other index, the national report could be output. The same disease level table, survey table and standard record table are designed in the system which needs to fill in. These data are connected in the database by programming and are calculated to fit the need of the report.

As a result of the system, we can obtain the required report while calculating the index of several data. The inquire function of the report is supported by the month, which could be printed according to the demands.

\subsection{The auxiliary function of GIS}

After connecting GIS and information management with VB and SuperMap Object 5.2, the auxiliary function is implemented, such as measuring the area and connecting the map together with the attribute tables. And of course, converting the data format is allowed.

The damage degree of every year and every month of the main disease could be inquired and showed on the map, with different pests and different diseases level.

\section{THE DETAILED DESIGN AND THE KEY TECHNIQUES}

\subsection{Designing of the system interface and the main function}

For the sake of the practical application, initialization of the system includes several parameters. When the area is definitely choose, the report will be output with the chosen area ID and other information automatically. The other operations are based on the chosen area (Fig. 1 and Fig. 2).

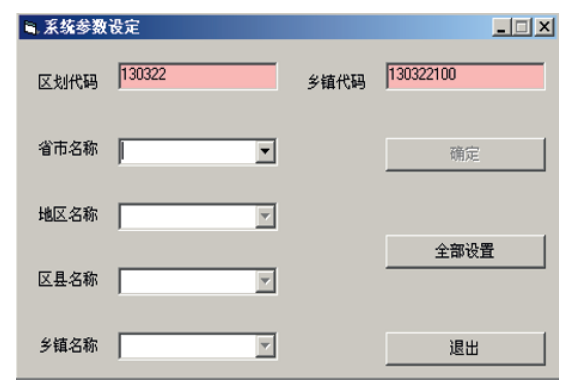

Fig. 2. The initial parameters

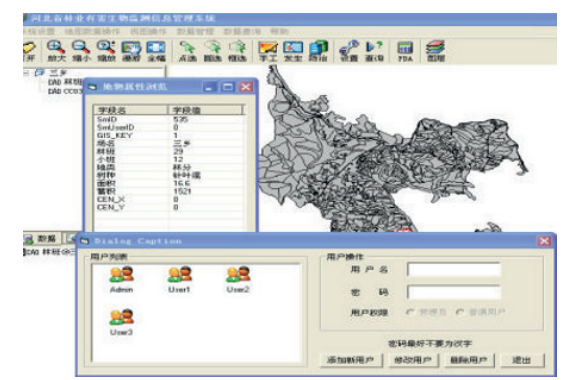

Fig. 2. User-management interface 
GIS had been introduced into the information management system of the diseases and pests, which could be visualized when inquiring the situation of the diseases. The function included: format reforming of the area, input the map, the attribute of the object in the map, mapping the thematic maps of diseases degree. The decision of preventing diseases could be helped to make on the intuitive map. Other GIS function as zoom out, zoom in, roam, full width were included (Fig. 3 and Fig. 4).

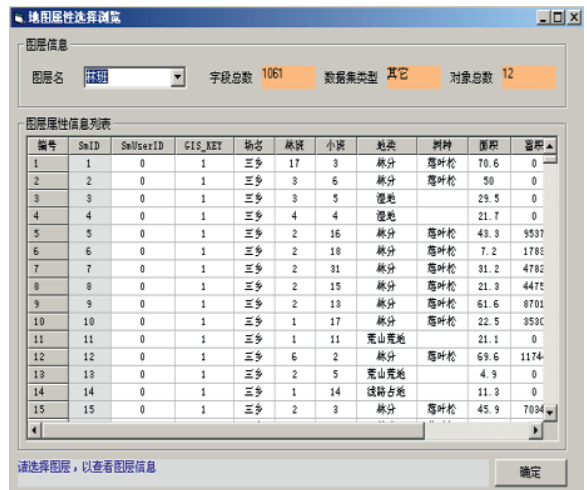

Fig. 3. The attribute of the subplot of the map

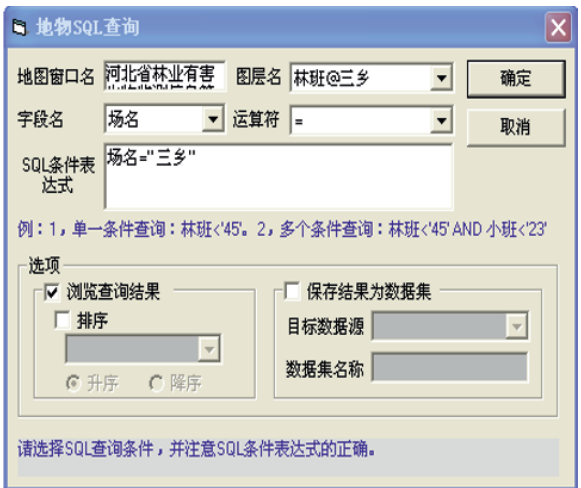

Fig. 4. SQL inquiring of subplot

Another important function is checking the area and the degree of the diseases through clicking the map. SQL inquiring of the condition after writing the ID of the subplot or the degree of the diseases, and the result is showed on the map (Fig. 5).

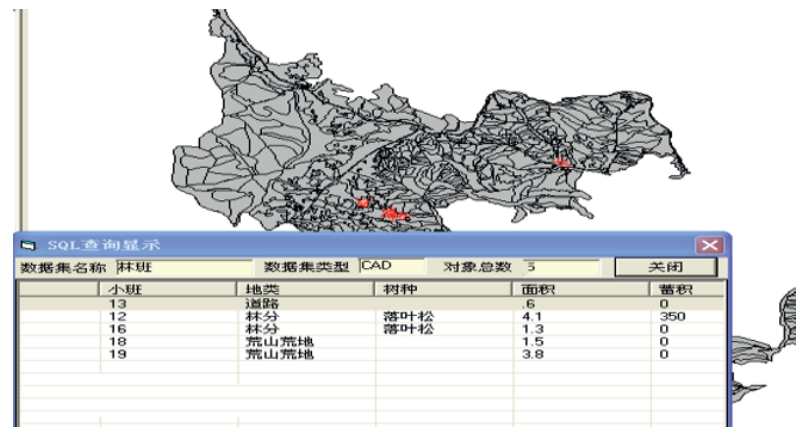

Fig. 5. High light of the inquiring result

As explained before, the data collected by PDA, which have three important tables in it is useful. Survey table (Fig. 7) include: survey table ID, inquirer, county code, name of county, diseases code, diseases name, generations, survey way, units, time and so on. The standard table (Fig. 6) include: the standard table ID, the survey table ID, diseases code, the own 
compartment, the own subplot, the degree. The same diseases level table (Fig. 8) included: same level table ID, the connected standard table ID, the own subplot of the forest, the own subplot, the area of the subplot, the preventing way.

When the inquirer starts a new survey, a new survey table is coming forth. The inquirer takes some typical subplot as the standard sample which will be the base of the other survey data such as the level of the damage. The same disease level table is filled of the data in which subplot has the same condition with the standard sample. The tables of the database have relations with each other. Among them, the survey table is the base of the standard table while the standard table is the base of the same disease level table. The ID of the tables has relationships between them. The ID rule of the survey table is:

$$
x \times-x \times \times-x \times \times \times \times x-x \times-x \times-x \times
$$

TC-the last three number of the country code-the diseases code-yearmonth-day

The ID rule of the standard table is:

$$
x \times \times-x \times x-x \times \times \times \times \times-x \times-x \times-x \times
$$

BZD-the last three number of the country-the diseases code-year-day

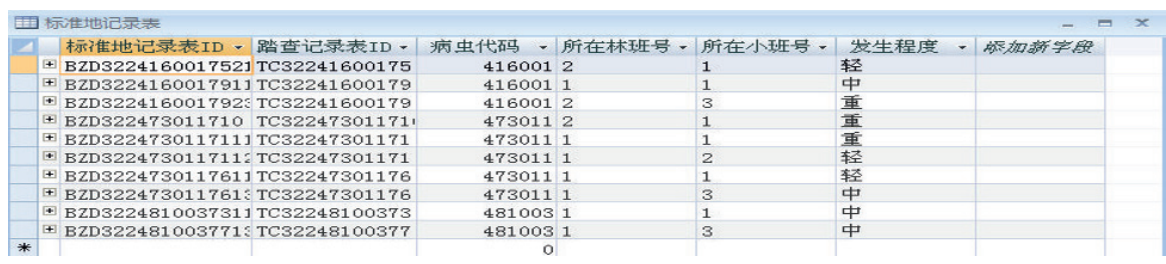

\begin{tabular}{|c|c|c|c|c|c|c|c|c|c|c|c|}
\hline \multicolumn{9}{|c|}{ 团 䠄查记录表 } & \multicolumn{3}{|c|}{$-a x$} \\
\hline 4 & & 踏查记录表ID & . & 乡镇代码 - & 乡镇名称 - & 病虫害代碚 一 & 病虫害名称 - & 世代/次 & - & 调查方法代 - & 计量! \\
\hline & † & TC32241600175 & & 322 & 12 & 416001 & 松突圆蚧 & & 1 & & 1 万亩 \\
\hline & 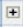 & TC32241600179 & & 322 & 12 & 416001 & 松突圆蚧 & & 2 & 1 & 1 万亩 \\
\hline & $\mp$ & TC32247301171 & & 322 & 12 & 473011 & 松毛虫 & & 1 & 1 & 1 万亩 \\
\hline & + & TC322473011710 & & 322 & 12 & 473011 & 松毛虫 & & 3 & & 1 万亩 \\
\hline & $\mp$ & TC 32247301176 & & 322 & 12 & 473011 & 松毛虫 & & 2 & & 1 万亩 \\
\hline & $\oplus$ & TC32248100373 & & 322 & 12 & 481003 & 美国白蛾 & & 1 & & 1 万亩 \\
\hline & † & TC32248100377 & & 322 & 12 & 481003 & 美国白蛾 & & 2 & & 1 万亩 \\
\hline * & & & & 0 & & & & & 0 & & 0 万亩 \\
\hline
\end{tabular}

Fig. 6. Standard table

Fig. 7. Survey table

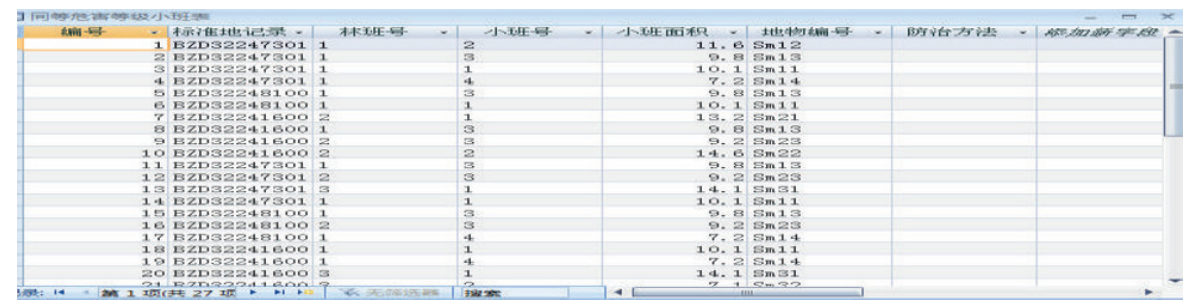

Fig. 8. Same diseases level table 
The connection of the tables is more important in this system. The information could be got outside or completed inside. When there is no PDA data could be input the system, the table could be filled out by hand through add or browse survey interface (Fig. 9). In this interface, the record of the survey data could be edited and browsed but could not new one. In the survey table management interface (Fig. 10), the record could be edited or deleted in a number. When the record of the standard table is selected in the right table, the related record of the survey table will be showed in left table (Fig. 10). The survey table ID is the primary key of the survey table while it is the foreign key of the standard table. Some of the survey table record will be also as the record of the standard table, and after ensuring the degree of the diseases, the other records will take it as the standard record. Those which record have the same degree with the standard record will be filled in the same diseases level table.

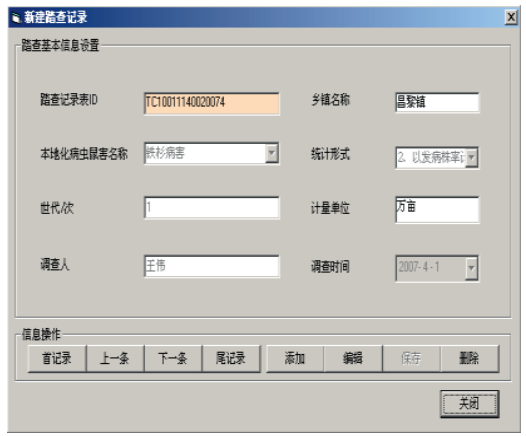

Fig. 9. Add or browse survey interface

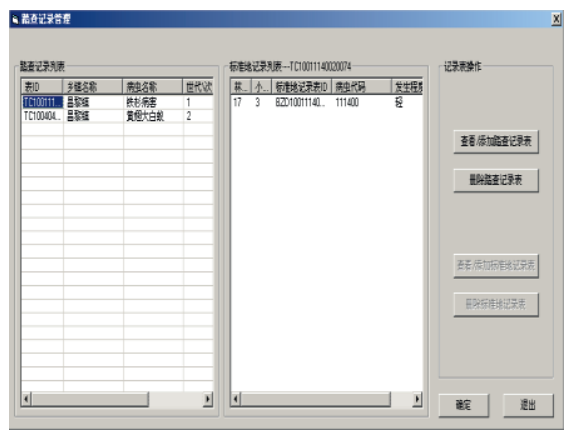

Fig. 10. Survey table management interface

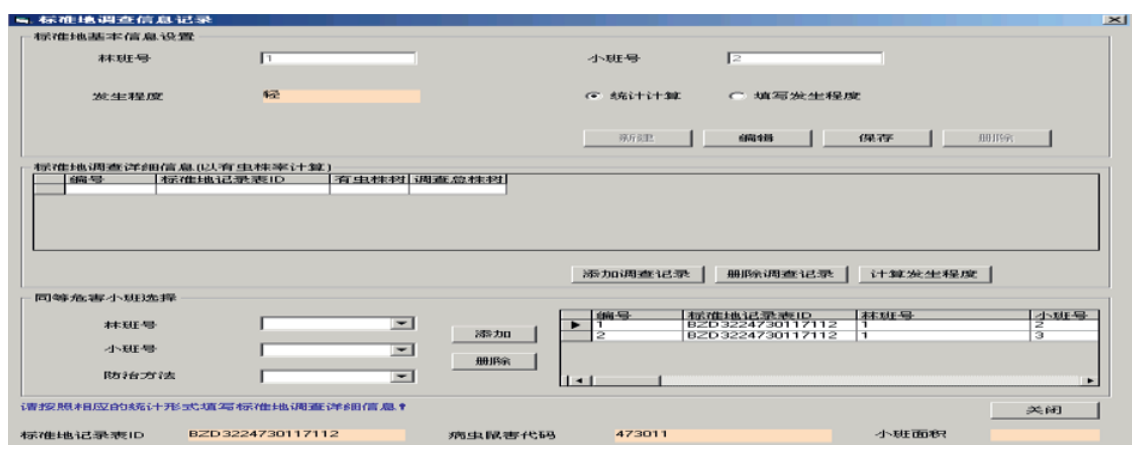

Fig. 11. Standard table management

The standard table management interface (Fig. 11) includes the basic information of the standard sample, the detail information of the standard sample and same diseases level. The detail information includes the kind of the diseases in the standard sample and the survey way, the total number of 
the area which will do goods to calculating the percentage of the diseases. According to the same preventing way of the same disease, the number of subplot is filled into the same diseases level table and use the same survey way. Or we could input the record through clicking the map. These three tables are the core of the database and have a key effect of report and other operation.

The report could be output after completing the necessary data of the table. As one of the final task of the system, the report include: occur report (Fig. 12), preventing report (Fig. 13), and total report.

The month report (Fig. 14) has been output with the name of the area, the name of the pests, generations, the host tree area, the distribution area and occur area, the new occur area and so on. The format is according to the national system and allowed to be printed in EXECL.

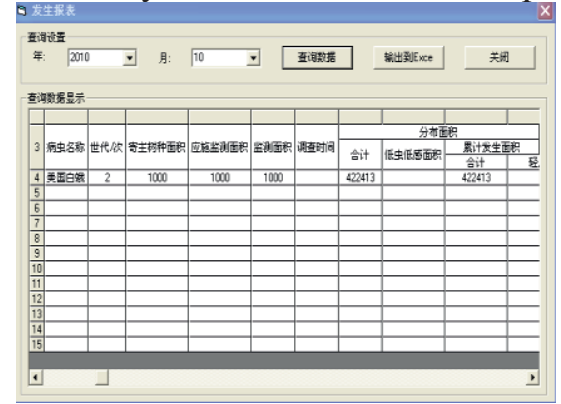

Fig. 12. Occur report

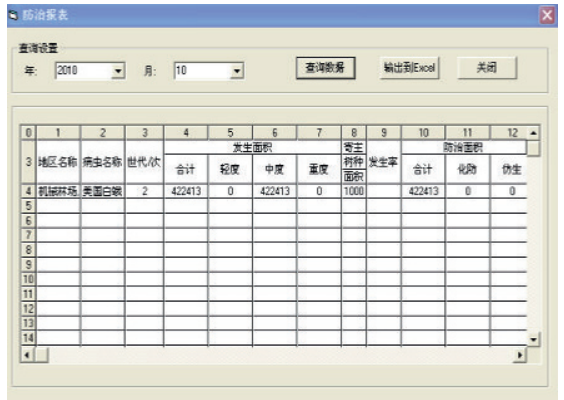

Fig. 13. Preventing report

Similarly the preventing report could be chose and output. The preventing report has some record of its own such as the preventing area and preventing way.

The total report is the most important table of the reports. The month or quarter or year report will be output in the total report. Especially the occur area (slight, medium, serious) and calculating the new occur are based on the third, sixth, ninth report of the national report.

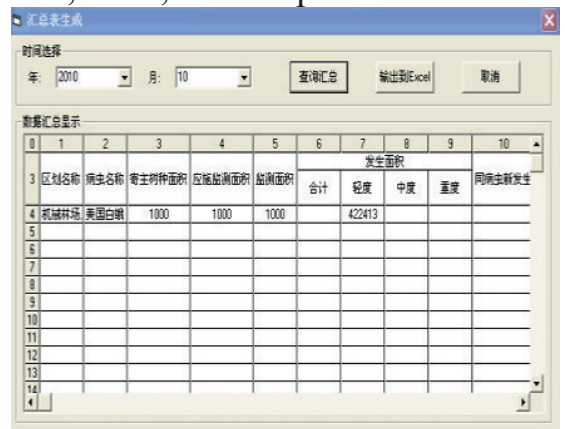

Fig. 14. The month report

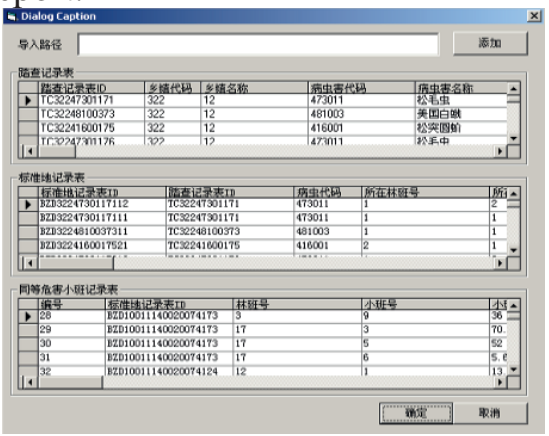

Fig. 15. Input the data into the system 


\subsection{The key technology in the system}

One of the important innovations is the use of PDA, which saves labor and money. Inquirer input the data into the PDA then lead it to the system which has the same interface with PDA (Fig. 15). When input into the system, the data of PDA is as a record in the database of the system. Then the data will be as the record used in the data management function.

Besides amount of the data, the tables have complicated relations between each other such as mathematics relations. The input interface of the system should be consistent with database and result in the output report.

\section{CONCLUSION AND PROSPECT}

The report data is complicated while the basic work is easy, especially some confusion concepts which lead to the wrong result. When fill the table by hand, some index are usually mistaken. On the GIS platform, some index such as area of the report will be calculated exactly. The occur percentage and prevent percentage is also done exactly. This has an important mean for the staff of the forest farm. And of course, the system based on GIS and information management is an innovation in forest area.

The next work is to realize the connection of the PDA and the INTERNET which will transport the data on time. And also adding the RS image is a bright future for monitoring. Forecasting the diseases will be another important work of the system.

\section{ACKNOWLEDGEMENTS}

Funding for this research was provided by NCET (Programme for New Century Excellent Talents in University, Project No. NCET-06-0122) and Innovative Research Team in University (Project No. IRT0607). The first author is grateful to Zhang Xiaoli professor for helping finishing the project.

\section{REFERENCES}

Cao Yanlong, "Pithiness of the system development based on Visual Basic ", 2005

Chen Libiao, Zhao Lianqing, "Considering of the development of HEIBEI forest resource information management", 2003

Guo Ruijun, "Pithiness of the database development of Visual Basic ", 2007 
He Ruizhen, Zhang Yin, Zhang Jingdong, "The designing and the development of the forest resource information management based on GIS",2005

He Zhengwei, Huang Runqiu, "The analysis of the forest information system development", 2004

Hong Lingxia, Lu Yuanchang, Lei Xiangdong, "The information system development of the country level", 2005

Li Xiaoli, Zhang Wei, "Examples of database system develop on Visual Basic+SQL Server", 2003

Liang Jun, Qu zhiwei, "The information system development of Chinese forest diseases", 2005

$\mathrm{Xu}$ Ruidong, "The study of forest resource information management system based on " $3 \mathrm{~s}$ " ", 2007

Zhang Yuan, Yin Mingfang, Wang Shuhai, "The study of the application of the forest resource management system", 2004

Zhong Qiuping, Li Diqiang, Li Jiangnan, "The development and the application of the resource management geographic system", 2001

Zhou Guona, Gao Baojia, "The application of GIS in the study of the plant diseases and pests",2003 